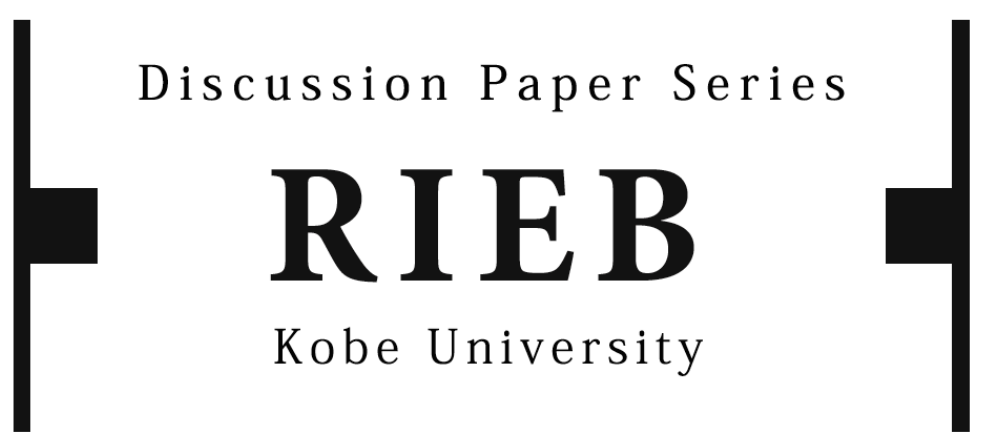

DP2016-17

Welfare Effects of Endogenous
Information Acquisition and
Disclosure in Duopoly Markets

Kazunori MIWA

March 30, 2016

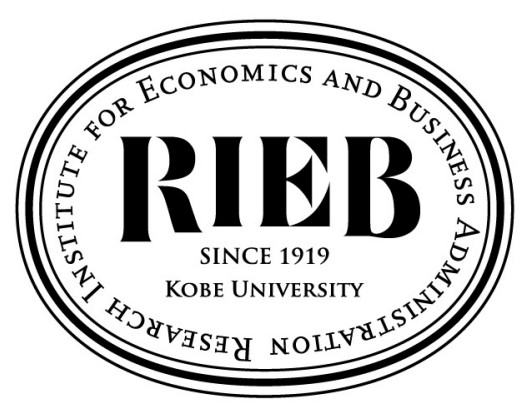

Research Institute for Economics and Business Administration Kobe University 


\title{
Welfare Effects of Endogenous
}

\section{Information Acquisition and Disclosure}

\section{in Duopoly Markets}

\author{
Kazunori Miwa ${ }^{\dagger}$
}

March 2016

${ }^{\dagger}$ Research Institute for Economics and Business Administration (RIEB), Kobe University, 2-1 Rokkodai, Nada, Kobe 657-8501, Japan. Email: miwa@rieb.kobe-u.ac.jp 


\title{
Welfare Effects of Endogenous Information Acquisition and Disclosure in Duopoly Markets
}

\begin{abstract}
This paper investigates the interaction between firms' information acquisition decisions and disclosure of internally acquired information in a Cournot duopoly market. The results are as follows. Given that the precision of firms' private information is constant, mandatory disclosure of information about the industry-wide demand uncertainty can enhance social welfare. However, when the precision of firms' private information is endogenously determined, mandatory disclosure is not always desirable. This is because when disclosure is mandated, firms acquire less precise information compared to the case where acquired information is not disclosed, and hence their internal information environments are deteriorated. This can lead to "unintended consequences," such that disclosure regulation strictly decreases social welfare on the whole.
\end{abstract}

Keywords: Information Acquisition; Disclosure; Duopoly; Social Welfare JEL Classification: L13; M41; M48 


\section{Introduction}

Accounting researchers recognize that management accounting systems (internal reporting) and financial accounting systems (external reporting) are closely linked (e.g., Hemmer and Labro, 2008; Taipaleenmäki and Ikäheimo, 2013; Zimmerman, 2014). However, as pointed out by Hemmer and Labro (2008), little is known about the interaction between them. Basically, external reporting or, more broadly, information disclosure, is monitored by regulatory agencies such as the Securities and Exchange Commission (SEC), Financial Accounting Standards Board (FASB), and International Accounting Standards Board (IASB), mainly in an attempt to protect decision makers in the capital market. One indication of this is that if external reporting (disclosure) is closely tied to management accounting (internal information) systems, then exogenously forced changes in disclosure rules might impact not only the information disclosed to outside users but also the information needed for firms' internal use. If so, regulatory agencies should consider the effect of disclosure regulation on firms' internal information environments and the resulting market outcomes in order to achieve the intended goal of the regulation. In fact, several recent studies suggest that exogenous changes in disclosure regulation also alter firms' internal information environments and affect subsequent managerial decisions (e.g., Graham, Hanlon, and Shevlin, 2011; Shroff, 2014; Shroff, Verdi, and $\mathrm{Yu}, 2014)$.

This paper adds to the theoretical insights in the above discussion by investigating the interaction between firms' information acquisition decisions and disclosure of the internally acquired information. Formally, this paper builds upon a standard duopoly model with uncertainty. It is well known that product market competition affects firms' disclosure decisions (e.g., Vives, 1984; Gal-Or, 1985; Darrough, 1993; Raith, 1996; Suijs and Wielhouwer, 2014). This paper extends the model by endogenizing firms' internal information acquisition decisions. In other words, a firm can choose the precision of private information before disclosing it. Under this setting, this paper attempts to answer the following questions. How does disclosure affect firms' information acquisition decisions? How does the interaction between information acquisition and disclosure 
affect social welfare? By answering these questions, the goal of this paper is to improve our understanding of how regulatory arrangements for external reporting affect firms' internal information environments and to evaluate the effectiveness of the disclosure regulation.

Duopolistic settings are appropriate for investigating the interaction between information acquisition and disclosure. ${ }^{1}$ Once privately acquired information is disclosed, a rival firm can also observe and strategically use it. If the disclosed information is also useful for the rival firm and improves its decision, then the disclosing firm might suffer a competitive disadvantage compared to the case in which information is withheld. This implies that disclosure will decrease the benefit obtained from acquiring costly information through the management accounting system. In addition, if a firm can free ride to some extent on the information disclosed by the other firm, then the free-riding firm's incentive to acquire costly private information through the management accounting system might diminish. Conversely, if disclosure can change the rival's behavior so that the disclosing firm benefits from revealing its private information, the firm might invest more in its internal information system and disclose the acquired private information. In this manner, it is possible that disclosure affects the potential costs or benefits of information acquisition depending on how the rival firm strategically responds to the disclosed information.

Notably, this paper focuses on the setting where two firms compete in quantities, that is, Cournot competition under industry-wide demand uncertainty. This is because previous analytical studies show that although Cournot duopolists commit to nondisclosure of private information related to industry-wide uncertainty, mandatory disclosure can enhance social welfare (e.g., Darrough, 1993; Suijs and Wielhouwer, 2014). This paper considers whether the regulatory implications suggested by the previous studies are valid when firms' private information is endogenously determined.

The main results are as follows. Given that the precision of firms' private information is constant, disclosure of information on industry-wide demand uncertainty can enhance

\footnotetext{
${ }^{1}$ In the context of the capital market, Pae (1999) analyzes the problem of information acquisition and disclosure.
} 
social welfare. Because firms have no incentives to voluntarily disclose their private information ex ante in this case, this implies that disclosure regulation is effective and socially desirable. This result is the same as that of prior studies and indicates that disclosure per se has a positive impact on social welfare (e.g., Suijs and Wielhouwer, 2014). However, in the setting where firms' private information is endogenously determined, mandatory disclosure is not always desirable. This is because disclosure has a negative effect on firms' incentives for acquiring private information through the internal information system. That is, when disclosure is mandated, firms acquire less precise information compared to the case where acquired information is not disclosed, and hence, their internal information environments are deteriorated. This leads to inefficient production decisions, which in turn, have a negative impact on social welfare. Taken together, mandating disclosure of privately acquired information has two effects on social welfare: (i) the direct positive effect, which increases social welfare as shown in the prior studies, and (ii) the negative indirect effect, which decreases social welfare through the deterioration of the internal information environment of the firm (Ganuza and Jansen, 2013). In fact, there exists a case where the negative indirect effect dominates the positive direct effect, that is, mandatory disclosure strictly decreases social welfare on the whole. This result is in sharp contrast to the findings of prior studies and suggests that disclosure regulation might fail to achieve the intended goal of enhancing social welfare.

This paper contributes to the literature on disclosure in duopoly markets by examining the interaction between firms' information acquisition and disclosure decisions. Numerous analytical studies examine firms' disclosure behavior in the presence of product market competition. ${ }^{2}$ However, most of the existing literature takes firms' private information as exogenous, and the interaction between firms' information acquisition and disclosure decisions is ignored. Notable exceptions are Kirby (2004), Jansen (2008),

\footnotetext{
${ }^{2}$ See, for example, Vives (1984), Gal-Or (1985), Kirby (1988), Vives (1990), Darrough (1993), Sankar (1995), Raith (1996), Clinch and Verrecchia (1997), Pae (2000), Pae (2002), Arya and Mittendorf (2007), Hughes and Williams (2008), Arya, Frimor, and Mittendorf (2010), Bagnoli and Watts (2010), Corona and Nan (2013), Suijs and Wielhower (2014), Bagnoli and Watts (2015), and Hughes and Pae (2015).
} 
and Ganuza and Jansen (2013). They simultaneously consider the problem of information acquisition and disclosure in a duopoly/an oligopoly. Kirby (2004) analyzes a stochastic oligopoly model and shows that mandatory disclosure requirements can create a potential opportunity loss for firms. Kirby (2004) assumes that firms act cooperatively in their choices of information acquisition and disclosure. Jansen (2008) also analyzes a stochastic duopoly model, but he focuses on strategic disclosure, that is, firms decide whether to disclose their private information or not after receiving the information. This paper is most closely related to that of Ganuza and Jansen (2013). They mainly analyze a Cournot-type duopoly model under firm-specific cost uncertainty, and show that disclosure increases firms' incentives to acquire private information.

Focusing on the effectiveness of the disclosure regulation, I provide additional insights by identifying the effects that disclosure has on firms' internal information acquisition decisions. Prior studies show that although Cournot duopolists prefer to not disclose industry-wide demand information ex ante, mandatory disclosure requirements can enhance social welfare. This paper argues that it is unclear whether mandatory disclosure can surely enhance social welfare. This is because mandatory disclosure might have a negative effect on firms' incentives to acquire costly private information. In fact, this paper identifies an important condition, namely, that social welfare is strictly reduced by mandatory disclosure.

This paper also has implications for disclosure regulation. Recent disclosure requirements make an attempt to expand firms' transparency and align their external and internal information environments. For example, Management Discussion \& Analysis (MD\&A) disclosure requires firms to provide information that enables outside investors to "see the firms through the eyes of management" (SEC, 2003). As a second example, the Statement of Financial Accounting Standards (SFAS) 131 and International Financial Reporting Standard (IFRS) 8 adopt the so-called "management approach" in segment reporting and require externally reported segments to be defined based on the firm's internal reporting structure. However, the analysis suggests that expanding firms' transparency through aligning externally disclosed information with that for firms' inter- 
nal use is not necessarily desirable. In particular, it is possible that mandatory disclosure of firms' private information has a negative impact on the incentives for acquiring information for firms' internal use, and ultimately deteriorates firms' internal information environments. This might lead to inefficient managerial decisions and decline of social welfare.

The remainder of this paper is organized as follows. Section 2 describes the model setup. In section 3, I analyze the model and provide the equilibrium strategies of the firms. In section 4, I examine the effect on social welfare and discuss the desirability of disclosure regulation. Section 5 summarizes the paper. All proofs are presented in the appendix.

\section{Model}

Consider a single-period product market where two firms $(i, j=1,2, i \neq j)$ compete in quantities, that is, Cournot duopoly market. ${ }^{3}$ The utility function of the representative consumer is assumed as follows.

$$
U\left(q_{1}, q_{2}\right)=\alpha\left(q_{1}+q_{2}\right)-\frac{\beta}{2}\left(q_{1}^{2}+q_{2}^{2}+2 \gamma q_{1} q_{2}\right)
$$

where $\alpha$ and $\beta$ are parameters, $q_{i} \geq 0$ is the quantity of firm $i$ 's product, and $0<$ $\gamma<\beta$ is the degree of substitution between firm 1's and firm 2's products. Note that $U$ is quadratic, (strictly) concave, and symmetric in $q_{1}$ and $q_{2}$ (Vives, 1984). The representative consumer maximizes $U\left(q_{1}, q_{2}\right)-\sum_{i=1}^{2} p_{i} q_{i}$, where $p_{i}$ is the price of firm $i$ 's product. Firm $i$ has a constant marginal cost, denoted by $c_{i}$. Without loss of generality, I assume that $\beta=1$ (hence, $\gamma \in(0,1))$ and $c_{i}=0$.

The first-order condition of the consumer's maximization problem gives the following

\footnotetext{
${ }^{3}$ The basic structure and notations of the model are based on Darrough (1993), Arya and Mittendorf (2007), and Suijs and Wielhouwer (2014).
} 
inverse demand function:

$$
p_{i}=\alpha-q_{i}-\gamma q_{j}
$$

I introduce uncertainty into the demand intercept. ${ }^{4}$ More specifically, following Darrough (1993) and Suijs and Wielhouwer (2014), I assume that

$$
\alpha=\bar{\alpha}+\Delta \alpha_{1}+\Delta \alpha_{2}
$$

where $\bar{\alpha}$ is a constant, and $\Delta \alpha_{1}$ and $\Delta \alpha_{2}$ are identically, independently, and normally distributed with mean zero and variance $s>0$.

Each firm $i$ acquires a costly and noisy signal about $\Delta \alpha_{i}$. The signal is denoted by $\xi_{i}$ and is expressed as

$$
\xi_{i}=\Delta \alpha_{i}+\varepsilon_{i}
$$

where $\varepsilon_{i}$ is normally distributed with mean zero and variance $e_{i}>0 .{ }^{5}$ The information acquisition cost, denoted by $K_{i}$, is assumed to be linear in $1 / e_{i}$. Equivalently, $K_{i}$ can be written as

$$
K_{i}\left(\eta_{i}\right)=\frac{k \eta_{i}}{s\left(1-\eta_{i}\right)}
$$

where $\eta_{i}=s /\left(s+e_{i}\right)$ and $k>0$ is a constant. ${ }^{6}$ Given that $\mathrm{E}\left[\Delta \alpha_{i} \mid \xi_{i}\right]=\eta_{i} \xi_{i}, \eta_{i}$ represents the sensitivity of the conditional expectation to the realized value of signal $\xi_{i}$. If $\eta_{i}$ is low, signal $\xi_{i}$ is not so valuable for firm $i$ in the sense that the conditional expectation

\footnotetext{
${ }^{4}$ Most theoretical studies that analyze firms' disclosure decisions in duopoly/oligopoly markets consider two types of uncertainty: demand uncertainty and cost uncertainty. In other words, firms have private information about market demand or their own production costs. In Cournot competition, however, the key distinction is between industry-wide versus firm-specific information, not between demand versus cost information (Christensen and Feltham, 2003, Ch.15).

${ }^{5}$ Following previous studies, despite the normality assumption about $\Delta \alpha_{i}$ and $\varepsilon_{i}$, I ignore the possibility of negative quantities. See, for example, Vives (1984, p.77, footnote 2), Darrough (1993, p.541, footnote 15), and Suijs and Wielhouwer (2014, p.232. footnote 8).

${ }^{6}$ This expression of the information acquisition cost is the same as that used by Hauk and Hurkens (2001).
} 
remains largely unaltered from the expected value of the prior. In contrast, if $\eta_{i}$ is high, firm $i$ relies more on the signal to update the prior belief. $\eta_{i} \in[0,1)$ because $e_{i}>0$. Hereafter, I refer to $\eta_{i}$ as the precision of the signal and work with $\eta_{i}{ }^{7}$

Each firm $i$ decides whether to disclose the acquired signal $\xi_{i}$. In order to make the analysis tractable, firm $i$ 's disclosure policy is represented by $\theta_{i} \in[0,1]$. In particular, firm $i$ chooses probability $\theta_{i}$ : signal $\xi_{i}$ acquired by firm $i$ is truthfully and publicly disclosed with probability $\theta_{i}$, and concealed with probability $1-\theta_{i}{ }^{8}$

The timeline of the model is as follows. First, each firm $i$ chooses its own disclosure policy $\theta_{i}$. Second, each firm $i$ chooses the precision of the signal. As stated above, acquiring signal $\xi_{i}$, the precision of which is $\eta_{i}$, costs $K_{i}\left(\eta_{i}\right)$. Then, each firm $i$ receives signal $\xi_{i}$, which is publicly disclosed or concealed according to the precommitted disclosure policy $\theta_{i}$. After observing the signal, each firm $i$ simultaneously chooses the quantity of product $q_{i}$. Note that signal $\xi_{j}$ of firm $j$ is also observed by firm $i$, if disclosed. Finally, products are sold on the market and each firm $i$ earns the profit, denoted by $\pi_{i}$. In terms of the amount, the final payoff for firm $i$, denoted by $\Pi_{i}$, is calculated by subtracting the information acquisition $\operatorname{cost} K_{i}\left(\eta_{i}\right)$ from the profit earned on sales $\pi_{i}$, that is, $\Pi_{i}=\pi_{i}-K_{i}\left(\eta_{i}\right)$.

In the sequence of events, both firms are assumed to commit themselves to disclosure policy before they acquire and observe the signal. Suijs and Wielhouwer (2014) point out that the precommitment assumption is justified in several settings. For example, it is likely that firms cannot strategically reconsider the disclosure policy on a case-bycase basis in settings where disclosure requires considerable changes in the information technology (IT) infrastructure or governance structure. In addition, the analysis of this ex ante setting makes it possible to examine the regulatory implications clearly.

\footnotetext{
${ }^{7}$ This definition about the precision of the signal is consistent with that of Ganuza and Jansen (2013). The information criterion of Ganuza and Jansen (2013), called Integral Precision, is based on "the principle that an information structure ... is more informative (more precise) than another if it generates more dispersed conditional expectations"(p.850).

${ }^{8}$ Ganuza and Jansen (2013) also use this formulation for the disclosure policy of the firm for the same reason as I do. See, Ganuza and Jansen (2013, p.850, footnote 9). As we will see in the following sections, corner solutions (i.e., $\theta_{i}=0$ or 1 ) arise according to the types of information and competition in voluntary disclosure settings. That is, in equilibrium, the signal acquired by each firm $i$ is fully disclosed or completely concealed.
} 
I assume that both firms are risk neutral and maximize their own expected payoffs. In the next section, I will solve the model backward.

\section{Equilibrium Strategies}

\subsection{Quantities of Products}

Each firm chooses the quantity of product in order to maximize the expected profit conditional on available information. ${ }^{9}$ There are three possibilities: (i) both firms disclose, (ii) only one of the two firms discloses, and (iii) neither firm discloses.

\subsubsection{If both firms disclose}

Consider case (i): both firms disclose. In this case, both firms can condition their production decisions on both signal values. Hence, firm $i$ 's quantity can be denoted by $q_{i}\left(\xi_{i}, \xi_{j}\right)$ and firm $i$ chooses its quantity in order to maximize the expected profit. ${ }^{10}$

$$
\begin{array}{r}
\max _{q_{i}\left(\xi_{i}, \xi_{j}\right)} \mathrm{E}\left[\left(\bar{\alpha}+\Delta \alpha_{i}+\Delta \alpha_{j}-q_{i}\left(\xi_{i}, \xi_{j}\right)-\gamma q_{j}\left(\xi_{j}, \xi_{i}\right)\right) q_{i}\left(\xi_{i}, \xi_{j}\right) \mid \xi_{i}, \xi_{j}\right], \\
i, j=1,2, \quad i \neq j .
\end{array}
$$

The first-order condition of the maximization problem of (6) gives the following best response function for firm $i$.

$$
\begin{aligned}
& \mathrm{E}\left[\bar{\alpha}+\Delta \alpha_{i}+\Delta \alpha_{j}-\gamma q_{j}\left(\xi_{j}, \xi_{i}\right)-2 q_{i}\left(\xi_{i}, \xi_{j}\right) \mid \xi_{i}, \xi_{j}\right]=0 \\
& \left.\Rightarrow \quad q_{i}=\frac{1}{2}\left(\bar{\alpha}+\mathrm{E}\left[\Delta \alpha_{i} \mid \xi_{i}\right]+\mathrm{E}\left[\Delta \alpha_{j} \mid \xi_{j}\right]-\gamma \mathrm{E}\left[q_{j}\left(\xi_{i}, \xi_{j}\right) \mid \xi_{i}, \xi_{j}\right]\right]\right) .
\end{aligned}
$$

Note that if we substitute the above first-order condition into the objective function (6), the expected profit of firm $i$ can be calculated as the square of its quantity. The best

\footnotetext{
${ }^{9}$ Note that the information acquisition cost is sunk at this stage.

${ }^{10}$ It is assumed that a firm cannot add noise or bias to its private signal when disclosing it. In addition, it is assumed that a firm knows the precision of a rival firm's signal if it is disclosed.
} 
response function of each firm yields the following optimal quantity choice.

$$
q_{i}^{d d}\left(\xi_{i}, \xi_{j}\right)=\frac{1}{2+\gamma}\left(\bar{\alpha}+\eta_{i} \xi_{i}\right)
$$

As superscript $d$ denotes disclosure, the two superscripts $d d$ in (8) denote disclosure by firm $i$ and firm $j$, respectively. Similarly, I use the superscript $\phi$ to denote nondisclosure. The ex ante expected profit of firm $i$ can be calculated using the law of iterated expectations and the fact that the expected profit of firm $i$ is the square of its quantity.

$$
\begin{aligned}
\mathrm{E}\left[\pi_{i}^{d d}\right] & =\left(\mathrm{E}\left[q_{i}^{d d}\left(\xi_{i}, \xi_{j}\right)\right]\right)^{2}+\operatorname{Var}\left[q_{i}^{d d}\left(\xi_{i}, \xi_{j}\right)\right] \\
& =\frac{1}{(2+\gamma)^{2}}\left(\bar{\alpha}^{2}+s \eta_{i}+s \eta_{j}\right) .
\end{aligned}
$$

\subsubsection{If only one firm discloses}

Next, consider case (ii): only one of the two firms discloses. I assume that firm $i$ discloses its signal and firm $j$ does not. Then, firm $i$ 's quantity is only conditional on its own signal whereas firm $j$ can choose its quantity using both signals. The maximization problem for each firm is as follows.

$$
\begin{aligned}
& \max _{q_{i}\left(\xi_{i}\right)} \mathrm{E}\left[\left(\bar{\alpha}+\Delta \alpha_{i}+\Delta \alpha_{j}-q_{i}\left(\xi_{i}\right)-\gamma q_{j}\left(\xi_{j}, \xi_{i}\right)\right) q_{i}\left(\xi_{i}\right) \mid \xi_{i}\right], \\
& \max _{q_{j}\left(\xi_{j}, \xi_{i}\right)} \mathrm{E}\left[\left(\bar{\alpha}+\Delta \alpha_{i}+\Delta \alpha_{j}-q_{j}\left(\xi_{j}, \xi_{i}\right)-\gamma q_{i}\left(\xi_{i}\right)\right) q_{j}\left(\xi_{j}, \xi_{i}\right) \mid \xi_{i}, \xi_{j}\right] .
\end{aligned}
$$

By applying the same procedure as in case (i), solving the problems denoted by (10) and (11) yields the following optimal quantity choice and the ex ante expected profit of 
each firm.

$$
\begin{aligned}
& q_{i}^{d \phi}=\frac{1}{2+\gamma}\left(\bar{\alpha}+\eta_{i} \xi_{i}\right), \\
& q_{j}^{\phi d}=\frac{1}{2+\gamma}\left(\bar{\alpha}+\frac{2+\gamma}{2} \eta_{j} \xi_{j}+\eta_{i} \xi_{i}\right), \\
& \mathrm{E}\left[\pi_{i}^{d \phi}\right]=\frac{1}{(2+\gamma)^{2}}\left(\bar{\alpha}^{2}+s \eta_{i}\right), \\
& \mathrm{E}\left[\pi_{j}^{\phi d}\right]=\frac{1}{(2+\gamma)^{2}}\left(\bar{\alpha}^{2}+\frac{(2+\gamma)^{2}}{4} s \eta_{j}+s \eta_{i}\right) .
\end{aligned}
$$

\subsubsection{If neither firm discloses}

Finally, consider case (iii): neither firm discloses. Each firm chooses its quantity conditional on its own signal because the rival firm's signal cannot be observed.

$$
\begin{aligned}
& \max _{q_{i}\left(\xi_{i}\right)} \mathrm{E}\left[\left(\bar{\alpha}+\Delta \alpha_{i}+\Delta \alpha_{j}-q_{i}\left(\xi_{i}\right)-\gamma q_{j}\left(\xi_{j}\right)\right) q_{i}\left(\xi_{i}\right) \mid \xi_{i}\right], \\
& i, j=1,2, \quad i \neq j .
\end{aligned}
$$

Solving the problem denoted by (16) for each firm yields the following optimal quantity choice and the ex ante expected profit of firm $i$.

$$
\begin{aligned}
& q_{i}^{\phi \phi}=\frac{1}{2+\gamma}\left(\bar{\alpha}+\frac{2+\gamma}{2} \eta_{i} \xi_{i}\right) \\
& \mathrm{E}\left[\pi_{i}^{\phi \phi}\right]=\frac{1}{(2+\gamma)^{2}}\left(\bar{\alpha}^{2}+\frac{(2+\gamma)^{2}}{4} s \eta_{i}\right)
\end{aligned}
$$

Combining the above three cases shows that the ex ante expected profit of firm $i$ when it chooses the optimal disclosure policy can be expressed as follows.

$$
\begin{aligned}
\mathrm{E}\left[\pi_{i}\right]= & \theta_{i}\left(\theta_{j} \mathrm{E}\left[\pi_{i}^{d d}\right]+\left(1-\theta_{j}\right) \mathrm{E}\left[\pi_{i}^{d \phi}\right]\right) \\
& +\left(1-\theta_{i}\right)\left(\theta_{j} \mathrm{E}\left[\pi_{i}^{\phi d}\right]+\left(1-\theta_{j}\right) \mathrm{E}\left[\pi_{i}^{\phi \phi}\right]\right)
\end{aligned}
$$

Firm $i$ chooses the precision of the signal and disclosure policy in order to maximize the expected profit in (19), taking into account the information acquisition cost. 


\subsection{Information Acquisition and Disclosure}

Now, consider the optimal information acquisition and disclosure policy for each firm. In the model, the firm's information acquisition decision is treated as its choice of signal precision. The maximization problem of firm $i$ is as follows.

$$
\max _{\eta_{i}} \mathrm{E}\left[\Pi_{i}\right]=\mathrm{E}\left[\pi_{i}\right]-K_{i}\left(\eta_{i}\right)
$$

Assuming that the optimal signal precision, denoted by $\eta_{i}^{*}$, is determined by the interior solution, the following first-order condition is satisfied. ${ }^{11}$

$$
\theta_{i} \frac{s}{(2+\gamma)^{2}}+\left(1-\theta_{i}\right) \frac{s}{4}-\frac{k}{s\left(1-\eta_{i}^{*}\right)^{2}}=0
$$

From the first-order condition in (21), the disclosure policy of the rival firm, $\theta_{j}$, does not affect firm $i$ 's information acquisition choice. One can obtain the following proposition about the interaction between information acquisition decision and disclosure policy by applying the implicit function theorem.

Proposition 1. The optimal signal precision of firm $i, \eta_{i}^{*}$, is negatively affected by its own disclosure policy, $\theta_{i}$, and is independent of the rival firm's disclosure policy, $\theta_{j}$.

Proposition 1 shows that disclosure has a negative impact on firms' activities to acquire the disclosed information. In other words, firms acquire more (less) precise information when the acquired information is concealed (disclosed).

Again using the implicit function theorem, the following comparative statics results can be readily obtained.

Corollary 1. The optimal signal precision of firm $i, \eta_{i}^{*}$, is

1. negatively affected by the parameter of information acquisition cost, $k$,

2. positively affected by the magnitude of uncertainty, s, and

\footnotetext{
${ }^{11}$ Note that the second derivative of the objective function is $-2 k / s\left(1-\eta_{i}\right)^{3}$; thus, the second-order condition is satisfied because $\eta_{i} \in[0,1)$.
} 
3. negatively affected by the degree of substitution between its own and the rival's products, $\gamma$, only when $\theta_{i}>0$.

The first and second results in Corollary 1 are intuitive. When each firm chooses signal precision, it must face a trade-off between the costs and benefits of acquiring the signal. Therefore, it is obvious that the lower the information acquisition cost, the more precise the signal acquired by the firm. In a similar way, the firm can obtain more benefit from the acquired signal under large uncertainty because the signal is helpful to mitigate the uncertainty and improve the firm's production decision. Thus, the larger the uncertainty, the more precise the signal acquired by the firm. The third result in Corollary 1 is related to the disclosure policy. In fact, when firm $i$ precommits to nondisclosure strategy, that is, $\theta_{i}=0$, the degree of substitution between the two firms' products has no effect on the optimal signal precision.

Given that $\eta_{i}=\eta_{i}^{*}$, firm $i$ chooses the optimal disclosure policy.

$$
\max _{\theta_{i}} \mathrm{E}\left[\Pi_{i}\left(\eta_{i}^{*}\right)\right]=\mathrm{E}\left[\pi_{i}\left(\eta_{i}^{*}\right)\right]-K_{i}\left(\eta_{i}^{*}\right)
$$

It is easy to show that the objective function in (22) is decreasing in $\theta_{i}$ when $\eta_{i}^{*}$ is determined by the interior solution. By contrast, when $\eta_{i}^{*}=0$, firm $i$ 's expected profit does not depend on $\theta_{i}$. Thus, the following proposition is derived.

Proposition 2. If $\eta_{i}^{*} \in(0,1)$, the optimal disclosure policy of firm $i$ is $\theta_{i}^{*}=0$, that is, nondisclosure. If $\eta_{i}^{*}=0$, any disclosure policy is indifferent for firm $i$.

This result is consistent with the findings of earlier studies, which demonstrate that Cournot duopolists prefer not to disclose industry-wide information ex ante (e.g., Darrough, 1993; Suijs and Wielhouwer, 2014).

The intuitions of Propositions 1 and 2 are explained as follows. Suppose that $\eta^{*} \in$ $(0,1)$ and firm $i$ obtains signal $\xi_{i}>0$. This means that the market demand is likely to be larger than the prior expectation. Thus, firm $i$ responds to the signal to increase its product quantity. The inverse is true if the signal value is negative, that is, $\xi_{i}<0$ : firm $i$ decreases its product quantity. 
If firm $i$ discloses signal $\xi_{i}>0$, then the rival firm $j$ can observe it and also increase its quantity. Because the quantities are strategic substitutes in a standard Cournot competition, this means that firm $i$ increases its quantity but the increase in the quantity is less than that in the nondisclosure case. ${ }^{12}$ Similarly, if firm $i$ obtains and discloses $\xi_{i}<$ 0 , firm $i$ decreases its quantity but the quantity is more than that in the nondisclosure case because firm $j$ also decreases its quantity by observing $\xi_{i}<0$. This implies that if firm $i$ discloses its private information, then the variance of its quantity decreases. However, the profit of firm $i$ is convex in its quantity; the ex ante expected profit of firm $i$ becomes larger as the variance increases. Taken together, disclosure decreases the $e x$ ante expected profit by decreasing the variance of the quantity. Hence, each firm has no incentive to voluntarily disclose its private information.

Now, consider the decisions about information acquisition. As stated above, the more precise the signal of firm $i$, the more heavily firm $i$ relies on the signal and adjusts its quantity. This increases the variance of the quantity, from the ex ante perspective, and thus increases the ex ante profit of firm $i$. However, this benefit from acquiring a more precise signal decreases if the acquired signal is disclosed because the rival firm $j$ can also use the disclosed signal and adjust its quantity in the same direction. Thus, the variance of the quantity and the ex ante profit of firm $i$ decreases. This is why disclosure has a negative effect on firms' information acquisition decisions.

\section{Welfare Analysis}

In this section, I examine how the interaction between information acquisition and disclosure affects social welfare. Following Suijs and Wielhouwer (2014), I consider consumer surplus and total surplus as measures of social welfare. The utility function of the representative consumer is given by (1). I define consumer surplus as $\mathrm{CS}=U\left(q_{1}, q_{2}\right)-\sum_{i=1}^{2} p_{i} q_{i}$ and total surplus as $\mathrm{TS}=\mathrm{CS}+\Pi_{1}+\Pi_{2}$. By substituting the inverse demand function given by (2) into the expression of the consumer surplus and

\footnotetext{
${ }^{12}$ See, Bulow, Geanakoplos, and Klemperer (1985) about strategic substitutes and complements.
} 
taking expectations, the expected consumer surplus can be expressed as follows. ${ }^{13}$

$$
\begin{aligned}
\mathrm{ECS}= & \theta_{i}\left(\theta_{j} \mathrm{ECS}^{d d}+\left(1-\theta_{j}\right) \mathrm{ECS}^{d \phi}\right) \\
& +\left(1-\theta_{i}\right)\left(\theta_{j} \mathrm{ECS}^{\phi d}+\left(1-\theta_{j}\right) \mathrm{ECS}^{\phi \phi}\right),
\end{aligned}
$$

where

$$
\begin{aligned}
\operatorname{ECS}^{d d} & =\frac{1+\gamma}{(2+\gamma)^{2}}\left(\bar{\alpha}^{2}+s \eta_{i}+s \eta_{j}\right), \\
\operatorname{ECS}^{d \phi} & =\frac{1+\gamma}{(2+\gamma)^{2}}\left(\bar{\alpha}^{2}+s \eta_{i}+\frac{(2+\gamma)^{2}}{8(1+\gamma)} s \eta_{j}\right), \\
\operatorname{ECS}^{\phi d} & =\frac{1+\gamma}{(2+\gamma)^{2}}\left(\bar{\alpha}^{2}+\frac{(2+\gamma)^{2}}{8(1+\gamma)} s \eta_{i}+s \eta_{j}\right), \\
\operatorname{ECS}^{\phi \phi} & =\frac{1+\gamma}{(2+\gamma)^{2}}\left(\bar{\alpha}^{2}+\frac{(2+\gamma)^{2}}{8(1+\gamma)} s \eta_{i}+\frac{(2+\gamma)^{2}}{8(1+\gamma)} s \eta_{j}\right)
\end{aligned}
$$

As in the former section, superscript $d$ and $\phi$ mean disclosure and nondisclosure, respectively. Similarly, the expected total surplus is given by

$$
\begin{aligned}
\operatorname{ETS}= & \theta_{i}\left(\theta_{j} \operatorname{ETS}^{d d}+\left(1-\theta_{j}\right) \operatorname{ETS}^{d \phi}\right) \\
& +\left(1-\theta_{i}\right)\left(\theta_{j} \operatorname{ETS}^{\phi d}+\left(1-\theta_{j}\right) \mathrm{ETS}^{\phi \phi}\right)
\end{aligned}
$$

where

$$
\begin{aligned}
& \operatorname{ETS}^{d d}=\frac{3+\gamma}{(2+\gamma)^{2}}\left(\bar{\alpha}^{2}+s \eta_{i}+s \eta_{j}\right)-\sum_{i=1}^{2} K_{i}, \\
& \operatorname{ETS}^{d \phi}=\frac{3+\gamma}{(2+\gamma)^{2}}\left(\bar{\alpha}^{2}+s \eta_{i}+\frac{3(2+\gamma)^{2}}{8(3+\gamma)} s \eta_{j}\right)-\sum_{i=1}^{2} K_{i}, \\
& \operatorname{ETS}^{\phi d}=\frac{3+\gamma}{(2+\gamma)^{2}}\left(\bar{\alpha}^{2}+\frac{3(2+\gamma)^{2}}{8(3+\gamma)} s \eta_{i}+s \eta_{j}\right)-\sum_{i=1}^{2} K_{i}, \\
& \operatorname{ETS}^{\phi \phi}=\frac{3+\gamma}{(2+\gamma)^{2}}\left(\bar{\alpha}^{2}+\frac{3(2+\gamma)^{2}}{8(3+\gamma)} s \eta_{i}+\frac{3(2+\gamma)^{2}}{8(3+\gamma)} s \eta_{j}\right)-\sum_{i=1}^{2} K_{i} .
\end{aligned}
$$

\footnotetext{
${ }^{13}$ The derivations of the expected consumer surplus are presented in the appendix.
} 
In preparation for the following analysis, first consider the effect of private signal precision on social welfare. Differentiating the expected consumer surplus and the expected total surplus with respect to firm $i$ 's signal precision gives the following lemma.

Lemma 1. Both the expected consumer surplus and the expected total surplus increase with firm i's signal precision, $\eta_{i}$.

Now I examine the effect of disclosure on social welfare. As a benchmark, consider the case where the precision of each firm's private signal is constant, namely, $\eta_{1}=\eta_{2}=\bar{\eta}$. An easy calculation leads to the following lemma.

Lemma 2. If the precision of each firm's private information is constant, that is, $\eta_{1}=$ $\eta_{2}=\bar{\eta}$, both the expected consumer surplus and the expected total surplus are (weakly) increasing functions of firm i's disclosure policy, $\theta_{i}$.

Notably, excepting the trivial case where firms' private signals have no information content, that is, $\bar{\eta}=0$, disclosure enhances both the expected consumer surplus and the expected total surplus. This indicates that disclosure per se has a positive impact on social welfare, which is consistent with the result of Suijs and Wielhouwer (2014).

However, the situation changes when the precision of each firm's private information is endogenously determined. In this case, following Ganuza and Jansen (2013), the effect of disclosure on the expected consumer surplus can be decomposed as follows.

$$
\frac{\partial \mathrm{ECS}}{\partial \theta_{i}}=\frac{\partial \mathrm{ECS}}{\partial \theta_{i}}+\frac{\partial \mathrm{ECS}}{\partial \eta_{i}} \frac{\partial \eta_{i}^{*}}{\partial \theta_{i}}+\frac{\partial \mathrm{ECS}}{\partial \eta_{j}} \frac{\partial \eta_{j}^{*}}{\partial \theta_{i}}
$$

The first term of (33) exhibits the direct effect of disclosure on the expected consumer surplus. Assuming that $\eta^{*}$ is determined by the interior solution, this direct effect is positive, that is, $\partial \mathrm{ECS} / \partial \theta_{i}>0$ as in Lemma 2 . On the other hand, the second term of (33) expresses the indirect effect in the sense that this captures the effect of disclosure on the expected consumer surplus through the change in firm's information acquisition decision caused by disclosure. As shown in Lemma 1, the expected consumer surplus is an increasing function of firm $i$ 's signal precision, that is, $\partial \mathrm{ECS} / \partial \eta_{i}>0$. However, 
Proposition 1 shows that disclosure negatively affects firm $i$ 's optimal signal precision, namely, $\partial \eta_{i}^{*} / \partial \theta_{i}>0$. Thus, as a whole, the indirect effect becomes negative. The third term of (33) is zero because $\partial \eta_{j}^{*} / \partial \theta_{i}=0$, as shown in Proposition 1. Taken together, disclosure has two effects on the expected consumer surplus: the positive direct effect and the negative indirect effect.

The effect of disclosure on the expected total surplus can also be decomposed as follows.

$$
\frac{\partial \mathrm{ETS}}{\partial \theta_{i}}=\frac{\partial \mathrm{ETS}}{\partial \theta_{i}}+\frac{\partial \mathrm{ETS}}{\partial \eta_{i}} \frac{\partial \eta_{i}^{*}}{\partial \theta_{i}}+\frac{\partial \mathrm{ETS}}{\partial \eta_{j}} \frac{\partial \eta_{j}^{*}}{\partial \theta_{i}}
$$

By applying the same procedure, one can immediately show the following. First, assuming that $\eta^{*}$ is determined by the interior solution, disclosure has a positive direct effect on the expected total surplus because $\partial \mathrm{ETS} / \partial \theta_{i}>0$. Second, however, disclosure also has a negative indirect effect because $\partial \mathrm{ETS} / \partial \eta_{i}>0$ but $\partial \eta_{i}^{*} / \partial \theta_{i}<0$. The last term of (34) is zero because $\partial \eta_{j}^{*} / \partial \theta_{i}=0$. The above results can be summarized as the following proposition.

Proposition 3. Disclosure of the signal that is privately and expensively acquired by each firm has two types of effects on the expected consumer surplus and expected total surplus: (i) the direct positive effect, which increases them and (ii) the negative indirect effect, which decreases them.

Proposition 3 indicates that if the positive direct effect dominates the negative indirect effect, then disclosure regulation will be effective and socially desirable. This is because, as shown in Proposition 2, each firm has no incentive to voluntarily disclose its own private signal but disclosure enhances social welfare.

In order to evaluate the effectiveness of the disclosure regulation, I focus on the two extreme cases: (i) perfect disclosure $\left(\theta_{1}=\theta_{2}=1\right.$, denoted by superscript $D$ ) and (ii) nondisclosure $\left(\theta_{1}=\theta_{2}=0\right.$, denoted by superscript $\left.N\right)$.

Consider the optimal signal precision in the case of perfect disclosure. From (21), the 
first-order condition is given by

$$
\left.\frac{\partial \mathrm{E}\left[\Pi_{i}\right]}{\partial \eta_{i}}\right|_{\theta_{i}=\theta_{j}=1}=\frac{s}{(2+\gamma)^{2}}-\frac{k}{s\left(1-\eta_{i}\right)^{2}}=0
$$

Because $\eta_{i} \in[0,1)$,

$$
\eta_{i}^{D}=\left\{\begin{array}{l}
\frac{s-(2+\gamma) \sqrt{k}}{s} \quad \text { if } \quad k \leq \frac{s^{2}}{(2+\gamma)^{2}} \\
0 \quad \text { if } \frac{s^{2}}{(2+\gamma)^{2}}<k
\end{array}\right.
$$

Similarly, for the case of nondisclosure, the first-order condition is

$$
\left.\frac{\partial \mathrm{E}\left[\Pi_{i}\right]}{\partial \eta_{i}}\right|_{\theta_{i}=\theta_{j}=0}=\frac{s}{4}-\frac{k}{s\left(1-\eta_{i}\right)^{2}}=0
$$

and

$$
\eta_{i}^{N}= \begin{cases}\frac{s-2 \sqrt{k}}{s} & \text { if } \quad k \leq \frac{s^{2}}{4} \\ 0 & \text { if } \quad \frac{s^{2}}{4}<k\end{cases}
$$

Apparently, the optimal precision of the signal that firm $i$ acquires is always higher under nondisclosure than under perfect disclosure except for the trivial case where $\eta_{i}^{D}=\eta_{i}^{N}=$ 0 . In addition, notice that $\eta_{i}^{D}=\eta_{j}^{D}$ and $\eta_{i}^{N}=\eta_{j}^{N}$ owing to the symmetric structure of the game.

Assuming that the optimal signal precision is determined by the interior solution, firm $i$ 's expected profit, expected consumer surplus, and expected total surplus in the case of perfect disclosure are calculated as follows, respectively.

$$
\begin{aligned}
& \mathrm{E}\left[\Pi_{i}^{\mathrm{D}}\right]=\frac{\bar{\alpha}^{2}}{(2+\gamma)^{2}}+\frac{(2 s-(2+\gamma) \sqrt{k})(s-(2+\gamma) \sqrt{k})}{(2+\gamma)^{2} s}, \\
& \operatorname{ECS}^{\mathrm{D}}=\frac{1+\gamma}{(2+\gamma)^{2}}\left(\bar{\alpha}^{2}+2(s-(2+\gamma) \sqrt{k})\right),
\end{aligned}
$$




$$
\operatorname{ETS}^{\mathrm{D}}=\frac{3+\gamma}{(2+\gamma)^{2}}\left(\bar{\alpha}^{2}+2 s\right)+\frac{2 k(2+\gamma)^{2}-2 s \sqrt{k}(2+\gamma)(4+\gamma)}{(2+\gamma)^{2} s}
$$

Similarly, firm $i$ 's expected profit, expected consumer surplus, and expected total surplus in the case of nondisclosure are calculated as follows, respectively.

$$
\begin{aligned}
& \mathrm{E}\left[\Pi_{i}^{\mathrm{N}}\right]=\frac{\bar{\alpha}^{2}}{(2+\gamma)^{2}}+\frac{(s-2 \sqrt{k})^{2}}{4 s} \\
& \operatorname{ECS}^{\mathrm{N}}=\frac{1+\gamma}{(2+\gamma)^{2}}\left(\bar{\alpha}^{2}+\frac{(2+\gamma)^{2}(s-2 \sqrt{k})}{4(1+\gamma)}\right), \\
& \operatorname{ETS}^{\mathrm{N}}=\frac{3+\gamma}{(2+\gamma)^{2}} \bar{\alpha}^{2}+\frac{3 s^{2}+8 k-10 s \sqrt{k}}{4 s} .
\end{aligned}
$$

Notice that when $k>s^{2} / 4$, the optimal precision of the signal becomes $\eta_{i}^{D}=\eta_{j}^{D}=$ $\eta_{i}^{N}=\eta_{j}^{N}=0$. Thus, the signal has no information content and disclosure does not affect social welfare. Consider the case where $k \leq s^{2} / 4$. Previous studies show that mandatory disclosure resolves the prisoner's dilemma and increases both firms' expected profits when their products are not good substitutes (e.g., Darrough, 1993; Suijs and Wielhouwer, 2014). However, the comparison between the equations (39) and (42) indicates that nondisclosure is still desirable for both firms even if their products are not good substitutes. In particular, the condition regarding whether disclosure regulation is desirable from the perspective of each firm is described as follows.

$$
\begin{aligned}
& \mathrm{E}\left[\Pi_{i}^{D}\right]>\mathrm{E}\left[\Pi_{i}^{N}\right] \quad \text { if } \quad 0<\gamma<2 \sqrt{2}-2 \quad \text { and } \quad k<\frac{\left(4-4 \gamma-\gamma^{2}\right)^{2} s^{2}}{16(1-\gamma)^{2}(2+\gamma)^{2}} \\
& \mathrm{E}\left[\Pi_{i}^{D}\right] \leq \mathrm{E}\left[\Pi_{i}^{N}\right] \quad \text { if } \quad \begin{cases}0<\gamma<2 \sqrt{2}-2 \quad \text { and } \quad \frac{\left(4-4 \gamma-\gamma^{2}\right)^{2} s^{2}}{16(1-\gamma)^{2}(2+\gamma)^{2}} \leq k \leq \frac{s^{2}}{4} \\
2 \sqrt{2}-2 \leq \gamma<1 \quad \text { and } \quad k \leq \frac{s^{2}}{4}\end{cases}
\end{aligned}
$$

More salient results can be viewed with regard to the expected consumer surplus and expected total surplus. Proposition 3 argues that disclosure has a positive direct effect 
and a negative indirect effect on the expected consumer surplus and the expected total surplus, respectively. The analysis demonstrates that there exists a situation where the negative indirect effect dominates the positive direct effect, that is, disclosure decreases social welfare on the whole. In particular, the conditions are as follows.

$$
\begin{aligned}
& \operatorname{ECS}^{D}>\operatorname{ECS}^{N} \quad \text { if } \quad k<\frac{\left(4+4 \gamma-\gamma^{2}\right)^{2} s^{2}}{4(2+\gamma)^{2}(2+3 \gamma)^{2}}, \\
& \operatorname{ECS}^{D} \leq \operatorname{ECS}^{N} \quad \text { if } \quad \frac{\left(4+4 \gamma-\gamma^{2}\right)^{2} s^{2}}{4(2+\gamma)^{2}(2+3 \gamma)^{2}} \leq k \leq \frac{s^{2}}{4}, \\
& \operatorname{ETS}^{D}>\operatorname{ETS}^{N} \quad \text { if } \quad k<\frac{\left(12-4 \gamma-3 \gamma^{2}\right)^{2} s^{2}}{4(6-\gamma)^{2}(2+\gamma)^{2}}, \\
& \operatorname{ETS}^{D} \leq \operatorname{ETS}^{N} \quad \text { if } \quad \frac{\left(12-4 \gamma-3 \gamma^{2}\right)^{2} s^{2}}{4(6-\gamma)^{2}(2+\gamma)^{2}} \leq k \leq \frac{s^{2}}{4} .
\end{aligned}
$$

These results contrast sharply to those of previous studies, which treat firms' private information as exogenous. As shown in Lemma 1, if the precision of the private signal is constant, then disclosure always increases both the expected consumer surplus and the expected total surplus. However, if the precision of the private signal is endogenously determined, disclosure has a negative impact on the signal precision and deteriorates firms' internal information environments. This negative impact of disclosure on signal precision decreases the expected consumer surplus and expected total surplus. In some situations, this negative indirect effect dominates the positive direct effect, and disclosure regulation leads to "unintended consequences," such that it decreases social welfare on the whole.

\section{Conclusion}

Although some researchers argue that management accounting systems (internal reporting) and financial accounting systems (external reporting) are closely linked, little is known about the interaction between them. This paper provides theoretical insights into this topic by investigating the interaction between firms' information acquisition 
decisions and disclosure of the internally acquired information. In particular, this paper builds upon a standard duopoly model with uncertainty and attempts to answer the following questions. How does disclosure affect firms' information acquisition decisions? How does the interaction between information acquisition and disclosure affect social welfare? By answering these questions, I hope to improve our understanding of how regulatory arrangements for external reporting affect firms' internal information environments and to evaluate the effectiveness of the disclosure regulation.

Specifically, this paper focuses on the setting where two firms compete in quantities, that is, Cournot competition under industry-wide demand uncertainty. Previous analytical studies show that although Cournot duopolists commit to nondisclosure of private information relating to industry-wide uncertainty, mandatory disclosure can enhance social welfare. However, the analysis shows that mandatory disclosure is not always desirable in the setting where firms' private information is endogenously determined. This is because disclosure has a negative effect on firms' incentives for acquiring private information through internal information systems. That is, when disclosure is mandated, firms acquire less precise information compared to the case where acquired information is not disclosed, and hence, their internal information environments are deteriorated. This can lead to "unintended consequences," such that disclosure regulation strictly decreases social welfare. In particular, this paper identifies the two effects on social welfare caused by mandating disclosure: (i) the direct positive effect, which increases social welfare as shown in the prior studies, and (ii) the negative indirect effect, which decreases social welfare through the deterioration of firms' internal information environments. In fact, there exists a case where the negative indirect effect dominates the positive direct effect, that is, mandatory disclosure decreases social welfare on the whole. This result is in sharp disagreement with that of prior studies and suggests that disclosure regulation might fail to achieve the intended goal of enhancing social welfare.

This paper suffers from several limitations. For example, in the model analysis, I assume that a firm cannot add noise or bias to its private signal when disclosing it. I also assume that a firm knows the precision of a rival firm's signal if it is disclosed. 
These assumptions are somehow restrictive and might be relaxed in future research in order to make the settings more realistic.

\section{Appendix}

\section{Derivation of equilibrium strategies for Cournot competition with industry-wide uncertainty}

First, consider the case where both firms disclose their private signals. In this case, both firms choose their quantities by observing signals $\xi_{i}$ and $\xi_{j}$. Thus, firm $i$ 's optimal quantity is denoted by $q_{i}^{d d}\left(\xi_{i}, \xi_{j}\right)$. Because information acquisition cost is sunk when firm $i$ chooses its quantity, it solves the following maximization problem.

$$
\begin{aligned}
& \max _{q_{i}\left(\xi_{i}, \xi_{j}\right)} \mathrm{E}\left[\pi_{i}^{d d} \mid \xi_{i}, \xi_{j}\right] \\
& =\left(\bar{\alpha}+\mathrm{E}\left[\Delta \alpha_{i} \mid \xi_{i}\right]+\mathrm{E}\left[\Delta \alpha_{j} \mid \xi_{j}\right]-q_{i}\left(\xi_{i}, \xi_{j}\right)-\gamma q_{j}\left(\xi_{j}, \xi_{i}\right)\right) q_{i}\left(\xi_{i}, \xi_{j}\right) .
\end{aligned}
$$

The first-order condition is given by

$$
\begin{aligned}
& \left.\frac{\partial}{\partial q_{i}\left(\xi_{i}, \xi_{j}\right)} \mathrm{E}\left[\pi_{i}^{d d} \mid \xi_{i}, \xi_{j}\right]\right|_{q_{i}\left(\xi_{i}, \xi_{j}\right)=q_{i}^{d d}\left(\xi_{i}, \xi_{j}\right)}=0 \\
& \Rightarrow \bar{\alpha}+\mathrm{E}\left[\Delta \alpha_{i} \mid \xi_{i}\right]+\mathrm{E}\left[\Delta \alpha_{j} \mid \xi_{j}\right]-2 q_{i}^{d d}\left(\xi_{i}, \xi_{j}\right)-\gamma q_{j}\left(\xi_{j}, \xi_{i}\right)=0 .
\end{aligned}
$$

Observe that substituting (A.2) in the objective function yields

$$
\mathrm{E}\left[\pi_{i}^{d d} \mid \xi_{i}, \xi_{j}\right]=\left(q_{i}^{d d}\left(\xi_{i}, \xi_{j}\right)\right)^{2}
$$

The second-order condition is satisfied as follows.

$$
\frac{\partial^{2}}{\partial\left(q_{i}\left(\xi_{i}, \xi_{j}\right)\right)^{2}} \mathrm{E}\left[\pi_{i}^{d d} \mid \xi_{i}, \xi_{j}\right]=-2<0
$$


From the first-order condition, one can obtain the following best response function for each firm,

$$
\begin{aligned}
& q_{i}\left(\xi_{i}, \xi_{j}\right)=\frac{1}{2}\left(\bar{\alpha}+\mathrm{E}\left[\Delta \alpha_{i} \mid \xi_{i}\right]+\mathrm{E}\left[\Delta \alpha_{j} \mid \xi_{j}\right]-\gamma \hat{q}_{j}\left(\xi_{j}, \xi_{i}\right)\right), \\
& q_{j}\left(\xi_{j}, \xi_{i}\right)=\frac{1}{2}\left(\bar{\alpha}+\mathrm{E}\left[\Delta \alpha_{i} \mid \xi_{i}\right]+\mathrm{E}\left[\Delta \alpha_{j} \mid \xi_{j}\right]-\gamma \hat{q}_{i}\left(\xi_{i}, \xi_{j}\right)\right),
\end{aligned}
$$

where $\hat{q}_{j}\left(\hat{q}_{i}\right)$ is firm $i$ 's (firm $j$ 's) conjecture of the quantity produced by firm $j$ (firm $i$ ). Notice that

$$
\mathrm{E}\left[\Delta \alpha_{i} \mid \xi_{i}\right]=\mathrm{E}\left[\Delta \alpha_{i}\right]+\frac{\operatorname{Cov}\left[\Delta \alpha_{i}, \xi_{i}\right]}{\operatorname{Var}\left[\xi_{i}\right]}\left(\xi_{i}-\mathrm{E}\left[\xi_{i}\right]\right)=\frac{s}{s+e_{i}} \xi_{i}=\eta_{i} \xi_{i}
$$

Assume the following linear (or strictly speaking, affine) strategy for each firm (Raith, 1996, Prop.3.1).

$$
\begin{aligned}
& q_{i}\left(\xi_{i}, \xi_{j}\right)=A_{0}^{i}+A_{1}^{i} \xi_{i}+A_{2}^{i} \xi_{j}, \\
& q_{j}\left(\xi_{j}, \xi_{i}\right)=A_{0}^{j}+A_{1}^{j} \xi_{j}+A_{2}^{j} \xi_{i} .
\end{aligned}
$$

Notice that $q_{i}\left(\xi_{i}, \xi_{j}\right)=\hat{q}_{i}\left(\xi_{i}, \xi_{j}\right)$ and $q_{j}\left(\xi_{j}, \xi_{i}\right)=\hat{q}_{j}\left(\xi_{j}, \xi_{i}\right)$ because both firms can observe signals $\xi_{i}$ and $\xi_{j}$. From equations (A.5) to (A.9), one can obtain

$$
\begin{aligned}
& 2\left(A_{0}^{i}+A_{1}^{i} \xi_{i}+A_{2}^{i} \xi_{j}\right)=\bar{\alpha}+\eta_{i} \xi_{i}+\eta_{j} \xi_{j}-\gamma\left(A_{0}^{j}+A_{1}^{j} \xi_{j}+A_{2}^{j} \xi_{i}\right), \\
& 2\left(A_{0}^{j}+A_{1}^{j} \xi_{j}+A_{2}^{j} \xi_{i}\right)=\bar{\alpha}+\eta_{j} \xi_{j}+\eta_{i} \xi_{i}-\gamma\left(A_{0}^{i}+A_{1}^{i} \xi_{i}+A_{2}^{i} \xi_{j}\right) .
\end{aligned}
$$

Comparing both sides of (A.10) and (A.11), and solving the simultaneous equations yields the following optimal quantity choice for each firm.

$$
\begin{aligned}
q_{i}^{d d}\left(\xi_{i}, \xi_{j}\right) & =\frac{1}{2+\gamma}\left(\bar{\alpha}+\eta_{i} \xi_{i}+\eta_{j} \xi_{j}\right), \\
q_{j}^{d d}\left(\xi_{j}, \xi_{i}\right) & =\frac{1}{2+\gamma}\left(\bar{\alpha}+\eta_{j} \xi_{j}+\eta_{i} \xi_{i}\right) .
\end{aligned}
$$

Now, consider the expected profit before observing the signals. Using the law of 
iterated expectations and equation (A.3),

$$
\begin{aligned}
\mathrm{E}\left[\pi_{i}^{d d}\right] & =\mathrm{E}\left[\mathrm{E}\left[\pi_{i}^{d d} \mid \xi_{i}, \xi_{j}\right]\right] \\
& =\left(\mathrm{E}\left[q_{i}^{d d}\left(\xi_{i}, \xi_{j}\right)\right]\right)^{2}+\operatorname{Var}\left[q_{i}^{d d}\left(\xi_{i}, \xi_{j}\right)\right]
\end{aligned}
$$

Notice that

$$
\mathrm{E}\left[q_{i}^{d d}\left(\xi_{i}, \xi_{j}\right)\right]=\frac{1}{2+\gamma} \bar{\alpha}
$$

and

$$
\begin{aligned}
\operatorname{Var}\left[q_{i}^{d d}\left(\xi_{i}, \xi_{j}\right)\right] & =\frac{1}{(2+\gamma)^{2}}\left(\eta_{i}^{2} \operatorname{Var}\left[\xi_{i}\right]+\eta_{j}^{2} \operatorname{Var}\left[\xi_{j}\right]\right) \\
& =\frac{1}{(2+\gamma)^{2}}\left(s \eta_{i}+s \eta_{j}\right)
\end{aligned}
$$

Thus,

$$
\begin{aligned}
\mathrm{E}\left[\pi_{i}^{d d}\right] & =\frac{1}{(2+\gamma)^{2}}\left(\bar{\alpha}^{2}+s \eta_{i}+s \eta_{j}\right) \\
\mathrm{E}\left[\pi_{j}^{d d}\right] & =\frac{1}{(2+\gamma)^{2}}\left(\bar{\alpha}^{2}+s \eta_{j}+s \eta_{i}\right)
\end{aligned}
$$

Applying similar procedures helps us derive the optimal quantities and expected profits for the other cases. Next, consider the case where firm $i$ discloses $\xi_{i}$ but firm $j$ withholds $\xi_{j}$. Then, firm $i$ can only use signal $\xi_{i}$ and firm $j$ can use both signals $\xi_{i}$ and $\xi_{j}$. Firm $i$ 's optimal quantity is denoted by $q_{i}^{d \phi}\left(\xi_{i}\right)$ and firm $j$ 's optimal quantity is denoted by $q_{j}^{\phi d}\left(\xi_{j}, \xi_{i}\right)$. The first-order conditions for the profit maximization problems yield the following best response functions.

$$
\begin{aligned}
& q_{i}\left(\xi_{i}\right)=\frac{1}{2}\left(\bar{\alpha}+\mathrm{E}\left[\Delta \alpha_{i} \mid \xi_{i}\right]-\gamma \hat{q}_{j}\left(\xi_{j}, \xi_{i}\right)\right) \\
& q_{j}\left(\xi_{j}, \xi_{i}\right)=\frac{1}{2}\left(\bar{\alpha}+\mathrm{E}\left[\Delta \alpha_{i} \mid \xi_{i}\right] \mathrm{E}\left[\Delta \alpha_{j} \mid \xi_{j}\right]-\gamma \hat{q}_{i}\left(\xi_{i}\right)\right) .
\end{aligned}
$$


Assume the following linear strategies.

$$
\begin{aligned}
& q_{i}\left(\xi_{i}\right)=A_{0}^{i}+A_{1}^{i} \xi_{i}, \\
& q_{j}\left(\xi_{j}, \xi_{i}\right)=A_{0}^{j}+A_{1}^{j} \xi_{j}+A_{2}^{j} \xi_{i} .
\end{aligned}
$$

Because firm $i$ cannot observe the realized value of $\xi_{j}$, its conjecture about firm $j$ 's quantity is

$$
\hat{q}_{j}\left(\xi_{j}, \xi_{i}\right)=A_{0}^{j}+A_{1}^{j} \mathrm{E}\left[\xi_{j}\right]+A_{2}^{j} \xi_{i}=A_{0}^{j}+A_{2}^{j} \xi_{i}
$$

Therefore,

$$
\begin{aligned}
& 2\left(A_{0}^{i}+A_{1}^{i} \xi_{i}\right)=\bar{\alpha}+\eta_{i} \xi_{i}-\gamma\left(A_{0}^{j}+A_{2}^{j} \xi_{i}\right) \\
& 2\left(A_{0}^{j}+A_{1}^{j} \xi_{j}+A_{2}^{j}\right)=\bar{\alpha}+\eta_{i} \xi_{i}+\eta_{j} \xi_{j}-\gamma\left(A_{0}^{i}+A_{1}^{i} \xi_{i}\right) .
\end{aligned}
$$

Solving the simultaneous equations yields the following optimal quantities.

$$
\begin{aligned}
& q_{i}^{d \phi}\left(\xi_{i}\right)=\frac{1}{2+\gamma}\left(\bar{\alpha}+\eta_{i} \xi_{i}\right) \\
& q_{j}^{\phi d}\left(\xi_{j}, \xi_{i}\right)=\frac{1}{2+\gamma}\left(\bar{\alpha}+\frac{2+\gamma}{2} \eta_{j} \xi_{j}+\eta_{i} \xi_{i}\right) .
\end{aligned}
$$

The expected profit before observing the signal(s) can be calculated as follows.

$$
\begin{aligned}
\mathrm{E}\left[\pi_{i}^{d \phi}\right] & =\left(\mathrm{E}\left[q_{i}^{d \phi}\left(\xi_{i}\right)\right]\right)^{2}+\operatorname{Var}\left[q_{i}^{d \phi}\left(\xi_{i}\right)\right] \\
& =\frac{1}{(2+\gamma)^{2}}\left(\bar{\alpha}^{2}+s \eta_{i}\right), \\
\mathrm{E}\left[\pi_{j}^{\phi d}\right] & =\left(\mathrm{E}\left[q_{j}^{\phi d}\left(\xi_{j}, \xi_{i}\right)\right]\right)^{2}+\operatorname{Var}\left[q_{j}^{\phi d}\left(\xi_{j}, \xi_{i}\right)\right] \\
& =\frac{1}{(2+\gamma)^{2}}\left(\bar{\alpha}^{2}+\frac{(2+\gamma)^{2}}{4} s \eta_{j}+s \eta_{i}\right) .
\end{aligned}
$$

Finally, consider the case where both firms do not disclose their signals. In this case, 
each firm can observe only the realization of its own signal. Thus, the optimal quantity of each firm is denoted by $q_{i}^{\phi \phi}\left(\xi_{i}\right)$ and $q_{j}^{\phi \phi}\left(\xi_{j}\right)$. The first-order conditions for the profit maximization problems yield the following best response functions.

$$
\begin{aligned}
& q_{i}\left(\xi_{i}\right)=\frac{1}{2}\left(\bar{\alpha}+\mathrm{E}\left[\Delta \alpha_{i} \mid \xi_{i}\right]-\gamma \hat{q}_{j}\left(\xi_{j}\right)\right) \\
& q_{j}\left(\xi_{j}\right)=\frac{1}{2}\left(\bar{\alpha}+\mathrm{E}\left[\Delta \alpha_{j} \mid \xi_{j}\right]-\gamma \hat{q}_{i}\left(\xi_{i}\right)\right) .
\end{aligned}
$$

Assume the following linear strategies.

$$
\begin{aligned}
& q_{i}\left(\xi_{i}\right)=A_{0}^{i}+A_{1}^{i} \xi_{i}, \\
& q_{j}\left(\xi_{j}\right)=A_{0}^{j}+A_{1}^{j} \xi_{j} .
\end{aligned}
$$

Because each firm cannot observe the realization of the rival's signal, the conjectures are as follows.

$$
\begin{aligned}
& \hat{q}_{j}\left(\xi_{j}\right)=A_{0}^{j}+A_{1}^{j} \mathrm{E}\left[\xi_{j}\right]=A_{0}^{j}, \\
& \hat{q}_{i}\left(\xi_{i}\right)=A_{0}^{i}+A_{1}^{i} \mathrm{E}\left[\xi_{i}\right]=A_{0}^{i} .
\end{aligned}
$$

Hence,

$$
\begin{aligned}
& 2\left(A_{0}^{i}+A_{1}^{i} \xi_{i}\right)=\bar{\alpha}+\eta_{i} \xi_{i}-\gamma A_{0}^{j}, \\
& 2\left(A_{0}^{j}+A_{1}^{j} \xi_{j}\right)=\bar{\alpha}+\eta_{j} \xi_{j}-\gamma A_{0}^{i} .
\end{aligned}
$$

Solving the simultaneous equations yields the following optimal quantities.

$$
\begin{aligned}
q_{i}^{\phi \phi}\left(\xi_{i}\right) & =\frac{1}{2+\gamma}\left(\bar{\alpha}+\frac{2+\gamma}{2} \eta_{i} \xi_{i}\right) \\
q_{j}^{\phi \phi}\left(\xi_{j}\right) & =\frac{1}{2+\gamma}\left(\bar{\alpha}+\frac{2+\gamma}{2} \eta_{j} \xi_{j}\right) .
\end{aligned}
$$


The expected profit before observing the signal can be calculated as follows.

$$
\begin{aligned}
\mathrm{E}\left[\pi_{i}^{\phi \phi}\right] & =\left(\mathrm{E}\left[q_{i}^{\phi \phi}\left(\xi_{i}\right)\right]\right)^{2}+\operatorname{Var}\left[q_{i}^{\phi \phi}\left(\xi_{i}\right)\right] \\
& =\frac{1}{(2+\gamma)^{2}}\left(\bar{\alpha}^{2}+\frac{(2+\gamma)^{2}}{4} s \eta_{i}\right) \\
\mathrm{E}\left[\pi_{j}^{\phi \phi}\right] & =\left(\mathrm{E}\left[q_{j}^{\phi \phi}\left(\xi_{j}\right)\right]\right)^{2}+\operatorname{Var}\left[q_{j}^{\phi \phi}\left(\xi_{j}\right)\right] \\
& =\frac{1}{(2+\gamma)^{2}}\left(\bar{\alpha}^{2}+\frac{(2+\gamma)^{2}}{4} s \eta_{j}\right)
\end{aligned}
$$

\section{Proof of Proposition 1}

The ex ante expected profit of firm $i$ can be expressed as follows.

$$
\begin{aligned}
\mathrm{E}\left[\pi_{i}\right]= & \theta_{i}\left(\theta_{j} \mathrm{E}\left[\pi_{i}^{d d}\right]+\left(1-\theta_{j}\right) \mathrm{E}\left[\pi_{i}^{d \phi}\right]\right) \\
& +\left(1-\theta_{i}\right)\left(\theta_{j} \mathrm{E}\left[\pi_{i}^{\phi d}\right]+\left(1-\theta_{j}\right) \mathrm{E}\left[\pi_{i}^{\phi \phi}\right]\right)
\end{aligned}
$$

Firm $i$ chooses the precision of signal $\xi_{i}$ in order to maximize its ex ante expected profit.

$$
\begin{aligned}
& \max _{\eta_{i}} \mathrm{E}\left[\pi_{i}\right]-K_{i}\left(\eta_{i}\right) \\
& =\mathrm{E}\left[\pi_{i}\right]-\frac{k \eta_{i}}{s\left(1-\eta_{i}\right)} .
\end{aligned}
$$

If we assume interior solution $\eta_{i}^{*}$, then the following first-order condition holds.

$$
\begin{aligned}
& \left.\frac{\partial}{\partial \eta_{i}}\left(\mathrm{E}\left[\pi_{i}\right]-K_{i}\left(\eta_{i}\right)\right)\right|_{\eta_{i}=\eta_{i}^{*}}=0 \\
& \Rightarrow \theta_{i} \frac{s}{(2+\gamma)^{2}}+\left(1-\theta_{i}\right) \frac{s}{4}-\frac{k}{s\left(1-\eta_{i}^{*}\right)^{2}}=0
\end{aligned}
$$

Observe that the second-order condition is satisfied as follows.

$$
\left.\frac{\partial^{2}}{\partial \eta_{i}^{2}}\left(\mathrm{E}\left[\pi_{i}\right]-K_{i}\left(\eta_{i}\right)\right)\right|_{\eta_{i}=\eta_{i}^{*}}=-\frac{2 k}{s\left(1-\eta_{i}^{*}\right)^{3}}<0 .
$$


We define

$$
F \equiv \theta_{i} \frac{s}{(2+\gamma)^{2}}+\left(1-\theta_{i}\right) \frac{s}{4}-\frac{k}{s\left(1-\eta_{i}^{*}\right)^{2}}
$$

The first-order condition requires $F=0$. Applying the implicit function theorem,

$$
\begin{aligned}
\frac{\partial \eta_{i}^{*}}{\partial \theta_{i}} & =-\frac{\partial F / \partial \theta_{i}}{\partial F / \partial \eta_{i}^{*}} \\
& =-\frac{\gamma(4+\gamma) s^{2}\left(1-\eta_{i}^{*}\right)^{3}}{8 k(2+\gamma)^{2}} \\
& <0 \\
\frac{\partial \eta_{i}^{*}}{\partial \theta_{j}} & =-\frac{\partial F / \partial \theta_{j}}{\partial F / \partial \eta_{i}^{*}} \\
& =0
\end{aligned}
$$

\section{Proof of Corollary 1}

Applying the implicit function theorem,

$$
\begin{aligned}
\frac{\partial \eta_{i}^{*}}{\partial k} & =-\frac{\partial F / \partial k}{\partial F / \partial \eta_{i}^{*}} \\
& =-\frac{1-\eta_{i}^{*}}{2 k} \\
& <0, \\
\frac{\partial \eta_{i}^{*}}{\partial s} & =-\frac{\partial F / \partial s}{\partial F / \partial \eta_{i}^{*}} \\
& =\frac{\left(1-\eta_{i}^{*}\right)\left[4 k(2+\gamma)^{2}+4 s^{2}\left(1-\eta_{i}^{*}\right)^{2}+\gamma(4+\gamma) s^{2}\left(1-\eta_{i}^{*}\right)^{2}\left(1-\theta_{i}\right)\right]}{8 k(2+\gamma)^{2} s} \\
& >0,
\end{aligned}
$$




$$
\begin{aligned}
\frac{\partial \eta_{i}^{*}}{\partial \gamma} & =-\frac{\partial F / \partial \gamma}{\partial F / \partial \eta_{i}^{*}} \\
& =-\frac{s^{2}\left(1-\eta_{i}^{*}\right)^{3} \theta_{i}}{k(2+\gamma)^{3}} \\
& \leq 0, \quad \text { with equality if and only if } \theta_{i}=0
\end{aligned}
$$

\section{Proof of Proposition 2}

Direct calculation shows that

$$
\frac{\partial}{\partial \theta_{i}}\left(\mathrm{E}\left[\pi_{i}\right]-\left.K_{i}\left(\eta_{i}\right)\right|_{\eta_{i}=\eta_{i}^{*}}\right)=-\frac{\gamma(4+\gamma) s \eta_{i}^{*}}{4(2+\gamma)^{2}}<0
$$

\section{Derivation of the expected consumer surplus}

From the definition of the consumer surplus,

$$
\mathrm{CS}=\alpha\left(q_{1}+q_{2}\right)-\frac{1}{2}\left(q_{1}^{2}+q_{2}^{2}+2 \gamma q_{1} q_{2}\right)-p_{1} q_{1}-p_{2} q_{2}
$$

Substituting the inverse demand function into the above equation,

$$
\mathrm{CS}=\frac{1}{2}\left(q_{1}^{2}+q_{2}^{2}+2 \gamma q_{1} q_{2}\right)
$$

Taking expectations for both sides of the above equation,

$$
\mathrm{ECS}=\frac{1}{2}\left(\mathrm{E}\left[q_{1}^{2}\right]+\mathrm{E}\left[q_{2}^{2}\right]+2 \gamma \mathrm{E}\left[q_{1} q_{2}\right]\right)
$$


Consider the case where both firms disclose their private signals. Then,

$$
\begin{aligned}
\mathrm{ECS}^{d d} & =\frac{1}{2}\left(\mathrm{E}\left[\left(q_{i}^{d d}\left(\xi_{i}, \xi_{j}\right)\right)^{2}\right]+\mathrm{E}\left[\left(q_{j}^{d d}\left(\xi_{j}, \xi_{i}\right)\right)^{2}\right]+2 \gamma \mathrm{E}\left[q_{i}^{d d}\left(\xi_{i}, \xi_{j}\right) q_{j}^{d d}\left(\xi_{j}, \xi_{i}\right)\right]\right) \\
& =\frac{1}{2}\left(\mathrm{E}\left[\pi_{i}^{d d}\right]+\mathrm{E}\left[\pi_{j}^{d d}\right]+2 \gamma \mathrm{E}\left[q_{i}^{d d}\left(\xi_{i}, \xi_{j}\right) q_{j}^{d d}\left(\xi_{j}, \xi_{i}\right)\right]\right)
\end{aligned}
$$

Observe that

$$
\begin{aligned}
& \mathrm{E}\left[q_{i}^{d d}\left(\xi_{i}, \xi_{j}\right) q_{j}^{d d}\left(\xi_{j}, \xi_{i}\right)\right] \\
& =\mathrm{E}\left[\frac{1}{2+\gamma}\left(\bar{\alpha}+\eta_{i} \xi_{i}+\eta_{j} \xi_{j}\right) \frac{1}{2+\gamma}\left(\bar{\alpha}+\eta_{j} \xi_{j}+\eta_{i} \xi_{i}\right)\right] \\
& =\mathrm{E}\left[\left(q_{i}^{d d}\left(\xi_{i}, \xi_{j}\right)\right)^{2}\right] \quad\left(=\mathrm{E}\left[\left(q_{j}^{d d}\left(\xi_{j}, \xi_{i}\right)\right)^{2}\right]\right) \\
& =\mathrm{E}\left[\pi_{i}^{d d}\right] \quad\left(=\mathrm{E}\left[\pi_{j}^{d d}\right]\right) .
\end{aligned}
$$

Therefore,

$$
\operatorname{ECS}^{d d}=\frac{1+\gamma}{(2+\gamma)^{2}}\left(\bar{\alpha}^{2}+s \eta_{i}+s \eta_{j}\right)
$$

Next, consider the case where firm $i$ discloses $\xi_{i}$ but firm $j$ withholds $\xi_{j}$.

$$
\begin{aligned}
\operatorname{ECS}^{d \phi} & =\frac{1}{2}\left(\mathrm{E}\left[\left(q_{i}^{d \phi}\left(\xi_{i}\right)\right)^{2}\right]+\mathrm{E}\left[\left(q_{j}^{\phi d}\left(\xi_{j}, \xi_{i}\right)\right)^{2}\right]+2 \gamma \mathrm{E}\left[q_{i}^{d \phi}\left(\xi_{i}\right) q_{j}^{\phi d}\left(\xi_{j}, \xi_{i}\right)\right]\right) \\
& =\frac{1}{2}\left(\mathrm{E}\left[\pi_{i}^{d \phi}\right]+\mathrm{E}\left[\pi_{j}^{\phi d}\right]+2 \gamma \mathrm{E}\left[q_{i}^{d \phi}\left(\xi_{i}\right) q_{j}^{\phi d}\left(\xi_{j}, \xi_{i}\right)\right]\right)
\end{aligned}
$$

Observe that

$$
\begin{aligned}
& \left.\mathrm{E}\left[q_{i}^{d \phi}\left(\xi_{i}\right) q_{j}^{\phi d}\left(\xi_{j}, \xi_{i}\right)\right]\right) \\
& =\mathrm{E}\left[\frac{1}{2+\gamma}\left(\bar{\alpha}+\eta_{i} \xi_{i}\right) \frac{1}{2+\gamma}\left(\bar{\alpha}+\frac{2+\gamma}{2} \eta_{j} \xi_{j}+\eta_{i} \xi_{i}\right)\right] \\
& =\frac{1}{(2+\gamma)^{2}} \bar{\alpha}^{2}+\frac{1}{(2+\gamma)^{2}} \eta_{i}^{2} \operatorname{Var}\left[\xi_{i}\right] \\
& =\frac{1}{(2+\gamma)^{2}}\left(\bar{\alpha}^{2}+s \eta_{i}\right) .
\end{aligned}
$$


Therefore,

$$
\operatorname{ECS}^{d \phi}=\frac{1+\gamma}{(2+\gamma)^{2}}\left(\bar{\alpha}^{2}+s \eta_{i}+\frac{(2+\gamma)^{2}}{8(1+\gamma)} s \eta_{j}\right)
$$

Finally, consider the case where both firms do not disclose their private signals.

$$
\begin{aligned}
\operatorname{ECS}^{\phi \phi} & =\frac{1}{2}\left(\mathrm{E}\left[\left(q_{i}^{\phi \phi}\left(\xi_{i}\right)\right)^{2}\right]+\mathrm{E}\left[\left(q_{j}^{\phi \phi}\left(\xi_{j}\right)\right)^{2}\right]+2 \gamma \mathrm{E}\left[q_{i}^{\phi \phi}\left(\xi_{i}\right) q_{j}^{\phi \phi}\left(\xi_{j}\right)\right]\right) \\
& =\frac{1}{2}\left(\mathrm{E}\left[\pi_{i}^{\phi \phi}\right]+\mathrm{E}\left[\pi_{j}^{\phi \phi}\right]+2 \gamma \mathrm{E}\left[q_{i}^{\phi \phi}\left(\xi_{i}\right) q_{j}^{\phi \phi}\left(\xi_{j}\right)\right]\right)
\end{aligned}
$$

Observe that

$$
\begin{aligned}
& \left.\mathrm{E}\left[q_{i}^{\phi \phi}\left(\xi_{i}\right) q_{j}^{\phi \phi}\left(\xi_{j}\right)\right]\right) \\
& =\mathrm{E}\left[\frac{1}{2+\gamma}\left(\bar{\alpha}+\frac{2+\gamma}{2} \eta_{i} \xi_{i}\right) \frac{1}{2+\gamma}\left(\bar{\alpha}+\frac{2+\gamma}{2} \eta_{j} \xi_{j}\right)\right] \\
& =\frac{1}{(2+\gamma)^{2}} \bar{\alpha}^{2} .
\end{aligned}
$$

Therefore,

$$
\operatorname{ECS}^{\phi \phi}=\frac{1+\gamma}{(2+\gamma)^{2}}\left(\bar{\alpha}^{2}+\frac{(2+\gamma)^{2}}{8(1+\gamma)} s \eta_{i}+\frac{(2+\gamma)^{2}}{8(1+\gamma)} s \eta_{j}\right)
$$

\section{Proof of Lemma 1}

For the expected consumer surplus, direct calculation shows that

$$
\frac{\partial \mathrm{ECS}}{\partial \eta_{i}}=\frac{\left((2+\gamma)^{2}+\left(4+4 \gamma-\gamma^{2}\right) \theta_{i}\right) s}{8(2+\gamma)^{2}}>0
$$

For, the expected total surplus, direct calculation shows that

$$
\frac{\partial \mathrm{ETS}}{\partial \eta_{i}}=\frac{(2+\gamma)^{2}\left(3 s^{2}\left(1-\eta_{i}\right)^{2}-8 k\right)+\left(12-4 \gamma-3 \gamma^{2}\right) s^{2}\left(1-\eta_{i}\right)^{2} \theta_{i}}{8(2+\gamma)^{2} s\left(1-\eta_{i}\right)^{2}}>0,
$$

because when $k>\left(3 s^{2}\left(1-\eta_{i}\right)^{2}\right) / 8, \eta_{i}$ does not have the interior solution and $\eta_{i}^{*}=0$. 


\section{Proof of Lemma 2}

Differentiating the expected consumer surplus and the expected total surplus with respect to firm $i$ 's disclosure policy $\theta_{i}$ given that $\eta_{1}=\eta_{2}=\bar{\eta}$,

$\left.\frac{\partial \mathrm{ECS}}{\partial \theta_{i}}\right|_{\eta_{i}=\eta_{j}=\bar{\eta}}=\frac{\left(4+4 \gamma-\gamma^{2}\right) s \bar{\eta}}{8(2+\gamma)^{2}} \geq 0$

with equality if and only if $\bar{\eta}=0$.

$\left.\frac{\partial \mathrm{ETS}}{\partial \theta_{i}}\right|_{\eta_{i}=\eta_{j}=\bar{\eta}}=\frac{\left(12-4 \gamma-3 \gamma^{2}\right) s \bar{\eta}}{8(2+\gamma)^{2}} \geq 0$

with equality if and only if $\bar{\eta}=0$.

\section{Proof of Proposition 3}

Proposition 3 is already proved by Proposition 1, Lemma 1, and Lemma 2.

\section{References}

[1] Arya, A., and B. Mittendorf. 2007. The Interaction among Disclosure, Competition between Firms, and Analyst Following. Journal of Accounting and Economics 43(2-3): 321-339.

[2] Arya, A., H. Frimor, and B. Mittendorf. 2010. Discretionary Disclosure of Proprietary Information in a Multisegment Firm. Management Science 56(4): 645-658.

[3] Bagnoli, M., and S. G. Watts. 2010. Oligopoly, Disclosure, and Earnings Management. The Accounting Review 85(4): 1191-1214.

[4] Bagnoli, M., and S. G. Watts. 2015. Competitive Intelligence and Disclosure. RAND Journal of Economics 46(4): 709-729. 
[5] Bulow, J. I., J. D. Geanakoplos, and P. D. Klemperer. 1985. Multimarket Oligopoly: Strategic Substitutes and Complements. Journal of Political Economy 93(3): 488-511.

[6] Christensen, P. O., and G. A. Feltham. 2003. Economics of Accounting: Volume I - Information in Markets. Springer, New York, NY.

[7] Clinch, G., and R. E. Verrecchia. 1997. Competitive Disadvantage and Discretionary Disclosure in Industries. Australian Journal of Management 22(2): 125137.

[8] Corona, C., and L. Nan. 2013. Preannouncing Competitive Decisions in Oligopoly Markets. Journal of Accounting and Economics 56(1): 73-90.

[9] Darrough, M. N. 1993. Disclosure Policy and Competition: Cournot vs. Bertrand. The Accounting Review 68(3): 534-561.

[10] Gal-Or, E. 1985. Information Sharing in Oligopoly. Econometrica 53(2): 329-343.

[11] Ganuza, J-J., and J. Jansen. 2013. Too Much Information Sharing? Welfare Effects of Sharing Acquired Cost Information in Oligopoly. Journal of Industrial Economics 61(4): 845-876.

[12] Graham, J. R., M. Hanlon, and T. Shelvin. 2011. Real Effects of Accounting Rules: Evidence from Multinational Firms' Investment Location and Profit Repatriation Decisions. Journal of Accounting Research 49(1): 137-185.

[13] Hauk, E., and S. Hurkens. 2001. Secret Information Acquisition in Cournot Markets. Economic Theory 18(3): 661-681.

[14] Hemmer, T., and E. Labro. 2008. On the Optimal Relation between the Properties of Managerial and Financial Reporting Systems. Journal of Accounting Research 46(5): 1209-1240. 
[15] Hughes, J. S., and M. G. Williams. 2008. Commitments and Disclosure in Oligopolies. The Accounting Review 83(1): 111-132.

[16] Hughes, J. S., and S. Pae. 2015. Discretionary Disclosure, Spillovers, and Competition. Review of Accounting Studies 20(1): 319-342.

[17] Jansen, J. 2008. Information Acquisition and Strategic Disclosure in Oligopoly. Journal of Economics and Management Strategy 17(1): 113-148.

[18] Kirby, A. J. 1988. Trade Association as Information Exchange Mechanisms. RAND Journal of Economics 19(1): 138-146.

[19] Kirby, A. J. 2004. The Product Market Opportunity Loss of Mandated Disclosure. Information Economics and Policy 16(4): 553-577.

[20] Pae, S. 1999. Acquisition and Discretionary Disclosure of Private Information and Its Implications for Firms' Productive Activities. Journal of Accounting Research $37(2): 465-474$.

[21] Pae, S. 2000. Information Sharing in the Presence of Preemptive Incentives: Economic Consequences of Mandatory Disclosure. Review of Accounting Studies 5(4): 331-350.

[22] Pae, S. 2002. Optimal Disclosure Policy in Oligopoly Markets. Journal of Accounting Research 40(3): 901-932.

[23] Raith, M. 1996. A General Model of Information Sharing in Oligopoly. Journal of Economic Theory 71(1): 260-288.

[24] Sankar, M. R. 1995. Disclosure of Predecision Information in a Duopoly. Contemporary Accounting Research 11(2): 829-859.

[25] Securities and Exchange Commission. 2003. Commission Guidance Regarding Management's Discussion and Analysis of Financial Condition and Results of Op- 
erations. Release No. 33-8350. FR No. 72. (Securities and Exchange Commission, Washington, DC).

[26] Shroff, N. 2014. Corporate Investment and Changes in GAAP. Working Paper, Available at SSRN: http://papers.ssrn.com/sol3/papers.cfm?abstract_id= 1977532.

[27] Shroff, N., R. S. Verdi, and G. Yu. 2014. Information Environment and the Investment Decisions of Multinational Corporations. The Accounting Review 89(2): 759-790.

[28] Suijs, J., and J. L. Wielhouwer. 2014. Disclosure Regulation in Duopoly Markets: Proprietary Costs and Social Welfare. European Accounting Review 23(2): 227255 .

[29] Taipaleenmäki, J., and S. Ikäheimo. 2013. On the Convergence of Management Accounting and Financial Accounting: The Role of Information Technology in Accounting Change. International Journal of Accounting Information Systems 14(4): 321-348.

[30] Vives, X. 1984. Duopoly Information Equilibrium: Cournot and Bertrand. Journal of Economic Theory 34(1): 71-94.

[31] Vives, X. 1990. Trade Association Disclosure Rules, Incentives to Share Information, and Welfare. RAND Journal of Economics 21(3): 409-430.

[32] Zimmerman, J. L. 2014. Accounting for Decision Making and Control (8th ed.). Irwin /McGraw Hill Publishing Company, New York, NY. 